\title{
An Innovative Approach to Supporting Hospitalist Physicians Towards Academic Success
}

\author{
Eric Howell, mD \\ Steven Kravet, MD, MBA \\ Flora Kisuule, MD, MPH \\ Scott M. Wright, MD
}

Collaborative Inpatient Medical Service (CIMS), Department of Medicine, Johns Hopkins University School of Medicine, Baltimore, Maryland
Dr. Wright is an Arnold P. Gold Foundation Associate Professor of Medicine and also receives support as a Miller-Coulson Family Scholar through the Johns Hopkins Center for Innovative Medicine.
BACKGROUND: Academic hospitalist physicians face significant challenges that may threaten their chances for successful and timely promotions, such as heavy clinical workloads, limited training in research, and relatively few experienced mentors in their field. The appreciable growth of hospital medicine groups in recent years, as has occurred at our institution, compounds the predicament by diluting the limited resources that are available to support these physicians.

METHODS: A needs assessment was followed by the development of specific objectives for the division and for individual members of the division related to academic success. The resulting 3-pronged strategy to support the academic success of our group was based on securing strong mentorship, investing requisite resources, and committing to recruit fellowship-trained new faculty.

RESULTS: To date, the initiative has resulted in an increased number of peerreviewed publication and grants, as well as national leadership roles for division members. Journal of Hospital Medicine 2008;3:314-318. ๑ 2008 Society of Hospital Medicine.

KEYWORDS: promotion, scholarship, research, mentoring.

D romotion through the ranks is the hallmark of success in academia. The support and infrastructure necessary to develop junior faculty members at academic medical centers may be inadequate. ${ }^{1,2}$ Academic hospitalists are particularly vulnerable and at high risk for failure because of their heavy clinical commitment and limited time to pursue scholarly interests. Further, relatively few have pursued fellowship training, which means that many hospitalists must learn research-related skills and the nuances of academia after joining the faculty.

Top-notch mentors are believed to be integral to the success of the academic physician. ${ }^{3-6}$ Among other responsibilities, mentors (1) direct mentees toward promising opportunities, (2) serve as advocates for mentees, and (3) lend expertise to mentees' studies and scholarship. In general, there is concern that the cadre of talented, committed, and capable mentors is dwindling such that they are insufficient in number to satisfy and support the needs of the faculty. ${ }^{7,8}$ In hospital medicine, experienced mentorship is particularly in short supply because the field is relatively new and there has been tremendous growth in the number of academic hospitalists, producing a large demand.

Like many hospitalist groups, our hospitalist division, the Collaborative Inpatient Medicine Service (CIMS), has experienced significant growth. It became apparent that the faculty needed and deserved a well-designed academic support program to foster the development of skills necessary for academic 
success. The remainder of this article discusses our approach toward fulfilling these needs and the results to date.

\section{DEVELOPING THE HOSPITALIST ACADEMIC SUPPORT PROGRAM \\ Problem Identification}

Johns Hopkins Bayview Medical Center (JHBMC) is a 700-bed urban university-affiliated hospital. The CIMS hospital group is a distinct division separate from the hospitalist group at Johns Hopkins Hospital. All faculty are employed by the Johns Hopkins University School of Medicine (JHUSOM), and there is a single promotion track for the faculty. Specific requirements for promotion may be found in the Johns Hopkins University School of Medicine "silver book" at http:// www.hopkinsmedicine.org/som/faculty/policies/ silverbook/. In reviewing the documentation, it became apparent that the haphazard approach to supporting this group of "junior" faculty members was not going to work and that a more organized and thoughtful plan was necessary. A culmination of the following factors at our institution spurred the innovation:

- CIMS had been growing in numbers from 4 fulltime equivalent (FTE) physicians in fiscal year (FY) 01 to 11.8 FTE physicians in FY06.

- Most had limited training in research.

- The physicians had little protected time for skill development and for working on scholarly projects.

- Attempts to recruit a professor-/associate professorlevel hospitalist from another institution to mentor our faculty members had been unsuccessful.

- The hospitalists in our group had diverse interests such that we needed to find a flexible mentor who was willing and able to work across a breadth of content areas and methodologies.

- Preliminary attempts to link up our hospitalists with clinician-investigators at our institution were not fruitful.

\section{Needs Assessment}

In soliciting input from the hospitalists themselves and other stakeholders (including institutional leadership and leaders in hospital medicine), the following needs were identified:

1. Each CIMS faculty member must have a body of scholarship to support promotion and long-term academic success.
2. Each CIMS faculty member needs appropriate mentorship.

3. Each CIMS faculty member needs protected time for scholarly work.

4. The CIMS faculty members need to support one another and be collaborative in their scholarly work.

5. The scholarly activities of the CIMS faculty need to support the mission of the division.

The mission of our division had been established to value and encourage the diverse interests and talents within the group:

\footnotetext{
"The Collaborative Inpatient Medical Service (CIMS) is dedicated to serving the public trust by advancing the field of Hospital Medicine through the realization of excellence in patient care, education, research, leadership, and systems-improvement."
}

\section{Objectives}

The objectives of the academic support program were organized into those for the CIMS Division as well as specific individual faculty goals and are outlined below:

A. Objectives for the division:

1. To increase the number and quality of peer-reviewed publications produced by CIMS faculty.

2. To increase the amount of scholarly time available to CIMS faculty. In addition to external funding sources, we were committed to exploring nontraditional funding sources such as hospital administration and partnerships with other divisions or departments (including information technology) in need of clinically savvy physicians to help with projects.

3. To augment the leadership roles of the CIMS faculty with our institution and on a national level.

4. To support the CIMS faculty members such that they can be promoted at Johns Hopkins University School of Medicine (JHUSOM) and thereby retained.

B. Goals for individuals:

1. Each CIMS faculty member will advance his or her skill set to be moving toward producing scholarly work independently.

2. Each faculty member will lead at least 1 scholarly project at all times and will be involved as a team-member in others.

3. Each faculty member will understand the criteria for promotion at our institution and will 
reflect on plans and strategies to realize success.

\section{Strategies for Achieving the Objectives and Goals Establish a Strong Mentoring System for the CIMS}

The CIMS identified a primary mentor for the group, a faculty member within the Division of General Internal Medicine who was an experienced mentor with formidable management skills and an excellent track record in publishing scholarly work. Twenty-percent of the mentor's time was set aside so he would have sufficient time to spend with CIMS faculty members in developing scholarly activities.

The mentor meets individually with each CIMS faculty member at the beginning of each academic year to identify career objectives; review current activities, interests, and skills; identify career development needs that require additional training or resources; set priorities for scholarly work; identify opportunities for collaboration internally and externally; and identify additional potential mentors to support specific projects. Regular follow-up meetings are arranged, as needed to review progress and encourage advancing the work. The mentor uses resources to stay abreast of relevant funding opportunities and shares them with the group. The mentor reports regularly to the director of the CIMS regarding progress. The process as outlined remains ongoing.

\section{Investing the Requisite Resources}

A major decision was made that CIMS hospitalists would have $30 \%$ of their time protected for academic work, without the need for external funding. The expectation that the faculty had to use this time to effectively advance their career goals, which in turn would support the mission of CIMS, was clearly and explicitly expressed. The faculty would also be permitted to decrease their clinical time further on obtaining external funding. Additionally, in conjunction with a specific grant, the group hired a research assistant to permanently support the scholarly work of the faculty.

Leaders in both hospital administration and the Department of Medicine agreed that the only way to maintain a stable group of mature hospitalists who could serve as champions for change and help develop functional quality improvement projects was to support them in their academic efforts, including protected academic time irrespective of external funding.

The funding to protect the scholarly commitment (the mentor, the protected time of CIMS faculty, and the research assistant) has come primarily from divisional funds, although the CIMS budget is subsidized by the Department of Medicine and the medical center.

\section{Recruit Faculty with Fellowship Training}

It is our goal to reach a critical mass of hospitalists with experience and advanced training in scholarship. Fellowship-trained faculty members are best positioned to realize academic success and can impart their knowledge and skills to others. Fellowship-trained faculty members hired to date have come from either general internal medicine $(n=1)$ or geriatric $(n=2)$ fellowship programs, and none have been trained in a hospitalist fellowship program. It is hoped that these fellowship-trained faculty and some of the other more experienced members of the group will be able to share in the mentoring responsibilities so that mentoring "outsourcing" can ultimately be replaced by CIMS faculty members.

\section{EVALUATION DATA}

In the 2 years since implementation of the scholarly support program, individual faculty in the CIMS have been meeting the above-mentioned goals. Specifically, with respect to acquiring knowledge and skills, 2 faculty members have completed their master's degrees, and 6 others have made use of select courses to augment their knowledge and skills. All faculty members $(100 \%)$ have a scholarly project they are leading, and most have reached out to a colleague in the CIMS to assist them, such that nearly all are team members on at least 1 other scholarly project. Through informal mentoring sessions and a once-yearly "formal meeting related to academic promotion," all members $(100 \%)$ of the faculty are aware of the expectations and requirements for promotion.

Table 1 shows the accomplishment of the 5 faculty members in the academic track who have been division members for 3 years or more. Among the 5 faculty in the academic track, publications and extramural funding are improving. In the 5 years before the initiative, CIMS faculty averaged approximately 0.5 publications per person per year; in the first 2 years of this initiative, that 
TABLE 1

Select Measures of Academic Success among Division Members Who Have Been on the Faculty for At Least 3 Years-Comparison Before and After Implementation of Academic Support Program (ASP)

\begin{tabular}{|c|c|c|c|c|c|c|}
\hline & Dr. $A^{*}$ & Dr. B & Dr. C & Dr. D & Dr. E & Dr. F \\
\hline Years on faculty & 7 & 7 & 7 & 5 & 3 & 3 \\
\hline Clinical \% FTE before ASP & $70 \%$ & $60 \%$ & $60 \%$ & $70 \%$ & $70 \%$ & $70 \%$ \\
\hline Clinical \% FTE after ASP ${ }^{\dagger}$ & Not applicable & $30 \%$ & $60 \%$ & $60 \%$ & $50 \%$ & $45 \%$ \\
\hline Number of publications per year before ASP & Not applicable & 0.75 & 0.75 & 0 & 0 & 0 \\
\hline Number of publications per year after ASP & Not applicable & 2.5 & 2 & 1 & 1 & 0 \\
\hline Leadership role and title before ASP: & Not applicable & & & & & \\
\hline a. within institution & & Yes & No & No & No & No \\
\hline b. national level & & No & No & No & No & No \\
\hline Leadership role and title after ASP: & Not applicable & & & & & \\
\hline a. within institution & & Yes & Yes & Yes & Yes & No \\
\hline b. national level & & Yes & No & No & No & Yes \\
\hline
\end{tabular}

* Dr. A left the academic track to become a clinical associate before implementation of the ASP.

${ }^{\dagger}$ For Doctors B, D, E, and F, the reduction in their clinical \% FTE was made possible through securing extramural research funding.

\$ The articles attributed to individuals are independent of each other such that articles are counted 1 time.

number has increased to 1.3 publications per person per year. The 1 physician who has not yet been published has completed projects and has several article in process. External funding (largely in the form of 3 extramural grants from private foundations) has increased dramatically from an average of $4 \%$ per FTE before the intervention to approximately $15 \%$ per FTE afterward. In addition, all faculty members have secured a source of additional funding to reduce their clinical efforts since the implementation of this program. One foundation funded project that involved all division members, whose goal was to develop mechanisms to improve the discharge process of elderly patients to their homes, won the award at the SGIM 2007 National Meeting for the best clinical innovation. As illustrated in Table 1, 1 of the founding CIMS members transferred out of the academic track in 2003 in alignment with this physician's personal and professional goals and preferences. Two faculty members have moved up an academic rank, and several others are poised to do so.

Thus, the divisional objectives (increasing number of publications, securing funding to increase the time devoted to scholarship, new leadership roles, and progression toward promotion) are being met as well.

\section{CONCLUSIONS}

Our rapidly growing hospitalist division recognized that several factors threatened the ability of the division and individuals to succeed academi- cally. Divisional, departmental, and medical center leadership was committed to creating a supportive structure that would be available to all hospitalists as opposed to expecting each individual to unearth the necessary resources on their own. The innovative approach to foster individual, and therefore divisional, academic and scholarly success was designed around the following strategies: retention of an expert mentor (who is a not a hospitalist) and securing $20 \%$ of his time, investing in scholarship by protecting $30 \%$ nonclinical time for academic pursuits, and attempting to seek out fellowship-trained hospitalists when hiring.

Although quality mentorship, protected time, and recruiting the best-available talent to fill needs may not seem all that innovative, we believe the systematic approach to the problem and our steadfast application of the strategic plan is unique, innovative, and may present a model to be emulated by other divisions. Some may contend that it is impossible to protect $30 \%$ FTE of academic hospitalists indefinitely. Our group has made substantial investment in supporting the academic pursuits of our physicians, and we believe this is essential to maintaining their satisfaction and commitment to scholarship. This amount of protected time is offered to the entire physician faculty and continues even as our division has almost tripled in size. This initiative represents a carefully calculated investment that has influenced our ability to recruit and retain excellent people. Ongoing prospective study of this intervention over time will provide additional 
perspective on its value and shortcomings. Nonetheless, early data suggest that the plan is indeed working and that our group is satisfied with the return on investment to date.

Address for correspondence and reprint requests: Scott Wright, MD, Division of General Internal Medicine, Johns Hopkins Bayview Medical Center, 4940 Eastern Avenue, Baltimore, MD, 21224; E-mail: smwright@jhmi.edu

Received 19 August 2007; revision received 22 January 2008; accepted 9 February 2008.

\section{REFERENCES}

1. Campbell EG, Weissman JS, Moy E, Blumenthal D. 2001. Status of clinical research in academic health centers: views from the research leadership. JAMA.286:800-806.

2. Shewan LG, Glatz JA, Bennett CC, Coats AJ. Contemporary (post-Wills) survey of the views of Australian medical researchers: importance of funding, infrastructure and motivators for a research career. Med J Aust. 2005;183:604-605.

3. Swazey JP, Anderson MS. Mentors, Advisors, and Role Models in Graduate and Professional Education. Washington DC: Association of Academic Health Centers; 1996.

4. Bland C, Schmitz CC. Characteristics of the successful researcher and implications for faculty development. $J$ Med Educ. 1986;61:22-31.

5. Barondess JA. On mentoring. $J$ R Soc Med. 1997;90:347349.

6. Palepu A, Friedman RH, Barnett RC, et al. Junior faculty members' mentoring relationships and their professional development in U.S. medical schools. Acad Med. 1998;73: 318-323.

7. AAMC (Association of American Medical Colleges). For the Health of the Public: Ensuring the Future of Clinical Research. Washington, DC: AAMC; 1999.

8. Wolf M. 2002. Clinical research career development: the individual perspective. Acad Med.77:1084-1088. 